\title{
Parathyroid carcinoma arising from auto- transplanted parathyroid tissue after Total Parathyroidectomy in chronic kidney disease patient: a case report
}

\author{
Ho-Ryun Won ${ }^{1}$, Jae Yoon Kang ${ }^{1}$, In Ho Lee ${ }^{2}$, Jin-Man Kim ${ }^{3}$, Jae Won Chang ${ }^{1}$ and Bon Seok Koo ${ }^{1 *}$
}

\begin{abstract}
Background: Secondary hyperparathyroidism is a common complication in patients with chronic kidney disease that requires vigilant treatment due to its high mortality rate. Pharmacologic therapy is recommended as an initial treatment; if there is no response, a total parathyroidectomy is performed. In some cases, surgery is accompanied by auto-transplantation of parathyroid tissue.

Case presentation: The patient was diagnosed with chronic kidney disease and received a kidney transplant. However, due to rejection of the transplanted kidney, medical nephrectomy was carried out and routine hemodialysis was initiated and observed. At this time, secondary hyperparathyroidism with elevated parathyroid hormone and hyperphosphatemia developed and pharmacologic treatment was applied. However, there was no response to pharmacologic treatment; therefore, total parathyroidectomy with auto-transplantation was performed. Eight years after surgery, a growing mass was observed in the transplantation site, accompanied by an elevation of parathyroid hormone. A complete resection of the mass was performed, and the patient was diagnosed with parathyroid carcinoma. Additional adjuvant radiation therapy was ordered, and the patient is being monitored.

Conclusions: This is a rare but remarkable case of parathyroid carcinoma arising from auto-transplanted parathyroid tissue after total parathyroidectomy in a patient with secondary hyperparathyroidism. We suggest caution should be taken when choosing to auto- transplant parathyroid tissue and that careful postoperative observation should be performed.
\end{abstract}

Keywords: Parathyroid carcinoma, Chronic kidney disease, Secondary hyperparathyroidism, Parathyroidectomy, Auto-transplantation

\section{Background}

Secondary hyperparathyroidism is a common complication in patients with chronic kidney disease (CKD) [1]. Prompt treatment of secondary hyperparathyroidism is critical because it causes a mineral disturbance in the body and is associated with an increased mortality rate in CKD patients [2]. Pharmacologic therapy is the firstline treatment; parathyroidectomy is only indicated

\footnotetext{
* Correspondence: bskoo515@cnuh.co.kr

${ }^{1}$ Department of Otolaryngology-Head and Neck Surgery, Chungnam National University College of Medicine, 640 Daesa-Dong, Chung-Gu, Daejeon 301-721, Republic of Korea

Full list of author information is available at the end of the article
}

when pharmacologic treatment is not effective or the side effects are severe [1].

Parathyroid carcinoma is a rare malignant tumor of endocrine origin. The most common cause of parathyroid carcinoma is primary hyperparathyroidism [3]. Other causes of this diseases are chronic stimulation due to secondary or tertiary hyperparathyroidism [4]. Differential diagnosis is important because both atypical parathyroid adenoma and parathyromatosis can occur in secondary hyperparathyroidism patients. The most important point in the differentiation of these diseases is the clinical features such as total serum calcium level and histological features after resection. Especially, parathyroid carcinoma

(c) The Author(s). 2019 Open Access This article is distributed under the terms of the Creative Commons Attribution 4.0 International License (http://creativecommons.org/licenses/by/4.0/), which permits unrestricted use, distribution, and 
has higher total serum calcium level than other diseases, and histologically, the invasion of surrounding tissues and blood vessels is characteristic [5].

We performed a total parathyroidectomy and autotransplantation of parathyroid tissue in a CKD patient with secondary hyperparathyroidism who did not respond to pharmacological treatment. Eight years after surgery, a solitary mass was palpated at the site of transplantation of the parathyroid tissue, and parathyroid hormone $(\mathrm{PTH})$ readings continuously increased. A complete excision was performed and the patient was diagnosed with parathyroid carcinoma based on the combined clinical and histological findings. To our knowledge, this is the first case of parathyroid carcinoma arising from auto-transplanted parathyroid tissue in a CKD patient with secondary hyperparathyroidism to be reported. We suggest caution be taken when choosing to auto-transplant parathyroid tissue in CKD patients with secondary hyperparathyroidism, and that careful longterm postoperative observation be performed.

\section{Case presentation}

The patient was diagnosed with type 2 diabetes for the first time at the age of 30; however, the patient was not treated. One year later, the patient visited the Department of Nephrology at Chungnam National University Hospital, where the patient was diagnosed with CKD due to uncontrolled diabetes mellitus and underwent continuous ambulatory peritoneal dialysis. Two years later, the patient received a kidney transplant at a hospital in China at the age of 33. After kidney transplantation, prednisolone, mycophenolate, tacrolimus and/or cyclosporin were used to prevent rejection. However, it was failed to maintain normal renal function; a kidney biopsy conducted a year later showed acute tubular necrosis with interstitial nephritis. After inserting a permanent catheter and undergoing hemodialysis, the patient visited the emergency room after a year due to right lower abdominal pain and was diagnosed with chronic rejection of the transplanted kidney. At age 35, the patient underwent medical nephrectomy of the transplanted kidney through embolization of the renal artery and started routine hemodialysis after receiving arteriovenous fistula surgery in the left forearm. Immunosuppressive therapy was maintained for up to a week after medical nephrectomy, and then discontinued.

During follow-up through an outpatient clinic, the patient presented with hyperphosphatemia $(5.5-9.2 \mathrm{mg} / \mathrm{dL}$ ) and lower limits of normal range of total calcium level $(8.6-9.0 \mathrm{mg} / \mathrm{d})$ (Normal range of serum total calcium levels in the laboratory of our institution: $8.7-10.5 \mathrm{mg} /$ d). Based on these findings, the patient was diagnosed with secondary hyperparathyroidism. The patient was given a regimen of calcium acetate, paricalcitol, cinacalcet, and sevelamer carbonate. However, the patient's PTH level increased to $827.6-1481 \mathrm{pg} / \mathrm{mL}$ during drug administration. In addition, hyperplastic parathyroid glands were found on the neck via computed tomography (CT) (Additional file 1 Figure S1). Finally, total parathyroidectomy with auto-transplantation was planned and performed at 38 years of age. A total of 4 hyperplastic parathyroid glands were removed (right superior parathyroid gland: $1.5 \times 0.9 \times 0.5 \mathrm{~cm}$ in size, left superior parathyroid gland: $1.0 \times 1.0 \times 0.7 \mathrm{~cm}$ in size, right inferior parathyroid gland: $1.5 \times 1.0 \times 0.5 \mathrm{~cm}$ in size, left inferior parathyroid gland: $2.0 \times 1.2 \times 0.9 \mathrm{~cm}$ in size). After confirming the parathyroid glands through frozen biopsy during operation, some parathyroid gland tissues were collected from left inferior parathyroid gland, and transplanted on the left sternocleidomastoid muscle. In the final pathologic report, all four parathyroid glands showed a histological glandular hyperplasia pattern. Postoperatively, the level of PTH remained at an average of $435.61 \mathrm{pg} / \mathrm{mL}$ and the level of phosphorus stabilized to an average of $6.08 \mathrm{mg} / \mathrm{dL}$ (Additional file 1 Figure S2).

However, 8 years after surgery, the patient's PTH level began fluctuating between 485 and $1399 \mathrm{pg} / \mathrm{mL}$ and his total calcium rose to an average of $9.8 \mathrm{mg} / \mathrm{dL}$ intermittently. However, normal levels of blood phosphorus were maintained $(5.34 \mathrm{mg} / \mathrm{dL}$ ) (Additional file 1 Figure S2). In addition, a solid, fixed, $3 \mathrm{~cm}$ mass was palpated at the implant site. A CT scan of the neck was performed and confirmed that the auto-transplanted parathyroid tissue had become enlarged and densely calcified (Fig. 1c, d). It had also increased to $2.5 \times 2.0 \times 2.0 \mathrm{~cm}$ in size, which was larger than what was seen at the 3 -year follow-up exam (Fig. 1a, b). Tc-99 m MIBI dual-phase parathyroid scintigraphy showed that the auto-transplanted parathyroid tissue was hyperfunctioning (Fig. 2d-f) compared to the 3-year follow-up (Fig. 2a-c) [6].

A complete resection of the auto-transplanted parathyroid tissue was performed at age 46 . The excised mass was $2 \times 2 \mathrm{~cm}$ in size with irregular margins and a calcareous composition (Fig. 3a). The final pathologic diagnosis was parathyroid carcinoma accompanied by surrounding muscle and vascular invasion (Fig. 3a-d). The resection margin was clear but had a closed margin (safety resection margin, $1 \mathrm{~mm}$ ). There was no local or distant metastasis on positron emission tomography-CT. Therefore, additional radiotherapy was ordered. Five months after complete resection of the autotransplanted parathyroid gland, the patient has completed adjuvant radiotherapy without specific complications or symptoms. PTH level remains stable.

\section{Discussion and conclusions}

The incidence of CKD is rising steadily with the increased prevalence of diabetes and hypertension [7]. The 

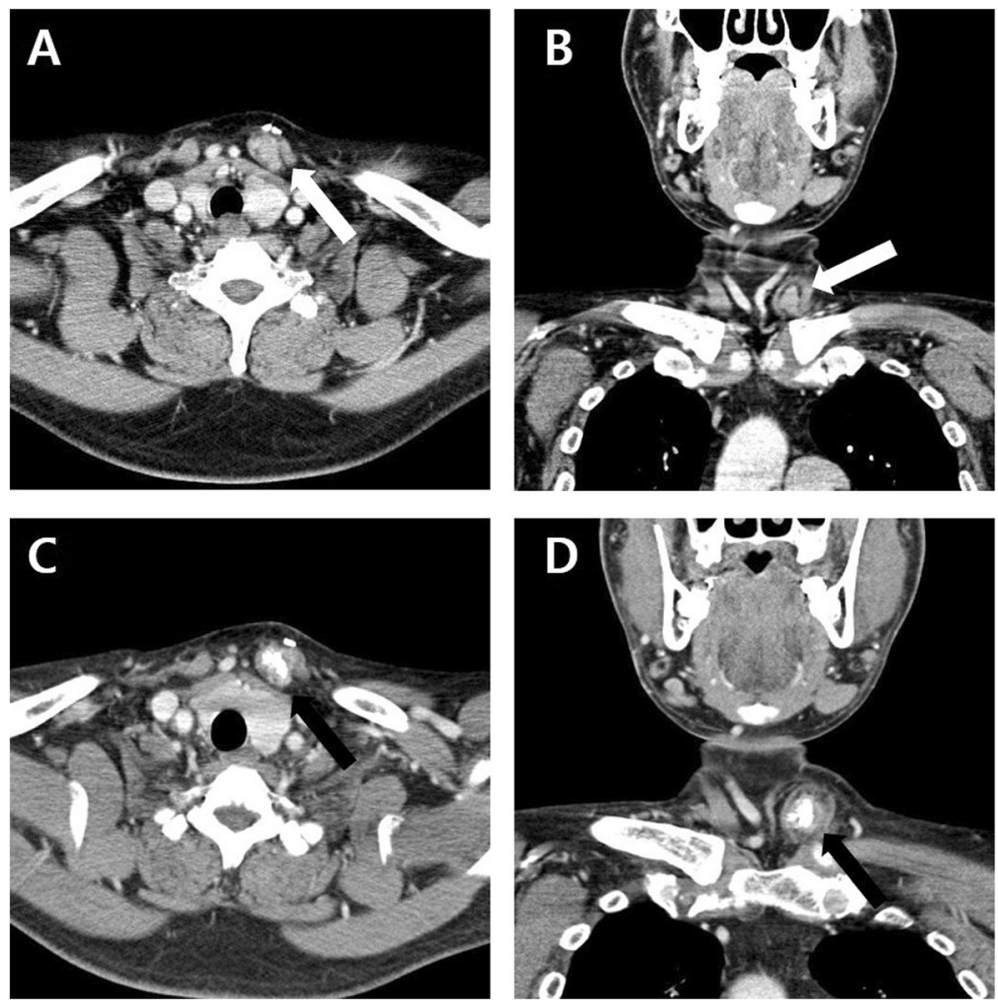

Fig. 1 Postoperative follow up neck CT. a b An enlarged mass considered as transplanted parathyroid tissue $(2.0 \times 1.7 \times 1.7 \mathrm{~cm}$ in size $)$ in the clavicular head of left sternocleidomastoid muscle (white arrow). Enhanced Neck CT performed 3 years after total parathyroidectomy with autotransplantation. (a) Axial view; (b) Coronal view; (c)(d) Compared with 3 years after surgery, a more enlarged mass with internal dense calcification $(2.5 \times 2.0 \times 2.0 \mathrm{~cm}$ in size) was found on the clavicular head of left sternocleidomastoid muscle (black arrow). Enhanced Neck CT performed 8 years after total parathyroidectomy with auto-transplantation. (c) Axial view; (d) Coronal view

severity of CKD is graded according to the glomerular filtration rate (GFR) [8]. Secondary hyperparathyroidism is a common complication in patients with CKD, especially in patients receiving dialysis [9]. Treatment of secondary hyperparathyroidism is important because it plays an important role in mineral bone disease and cardiovascular diseases associated with CKD $[9,10]$. Despite many advances in dialysis treatment, there has been no significant change in the mortality rate of CKD patients, and the disturbance in mineral and bone metabolism by secondary hyperparathyroidism is a major cause of such mortality [11-13].

Secondary hyperparathyroidism in CKD patients is caused by hyperphosphatemia, which is a major pathophysiologic mechanism [7]. The reduction in GFR leads to a decrease in phosphorus clearance, which results in phosphorus retention. In this hyperphosphatemic state, 1,25-dihydroxyvitamin $\mathrm{D}$ is decreased by the increase in fibroblast growth factor 23 [14-16]. This eventually leads to hypocalcemia, which stimulates the parathyroid to induce continuous secretion of PTH $[7,15,17]$. This is a normal regulatory response in low-grade CKD. However, if the effect of PTH on phosphorus reabsorption is reduced due to the deterioration of renal function, PTH continuously increases and eventually causes a disturbance in mineral and bone metabolism [7, 15]. The increased phosphorus causes further secretion of PTH, and PTH persists in a vicious cycle leading to hyperphosphatemia [7].

Pharmacological intervention is considered the firstline treatment for secondary hyperparathyroidism. Pharmacologic therapy is based on calcimimetics, calcitriol, and vitamin $\mathrm{D}$ analogs, including vitamin $\mathrm{D} \mathrm{mi-}$ metics [18]. Phosphorus binders for the control of hyperphosphatemia are also used for treatment $[19,20]$. Parathyroidectomy is only considered when there is no response to pharmacologic therapy or when its side effects are too severe [21]. According to recent 2017 Kidney Disease: Improving Global Outcomes guidelines, parathyroidectomy is indicated for patients at all stages of CKD ranging from early GFR decline $(60 \mathrm{ml} / \mathrm{min}$ per $1.73 \mathrm{~m}^{2}$ ) to dialysis when there is no response to pharmacologic therapy. In addition, the incidence of parathyroidectomy is gradually increasing [22]; one study reported that parathyroidectomy was performed in 15\% of patients who received dialysis for 10 years and in 38\% of patients who received dialysis for 20 years [23]. 

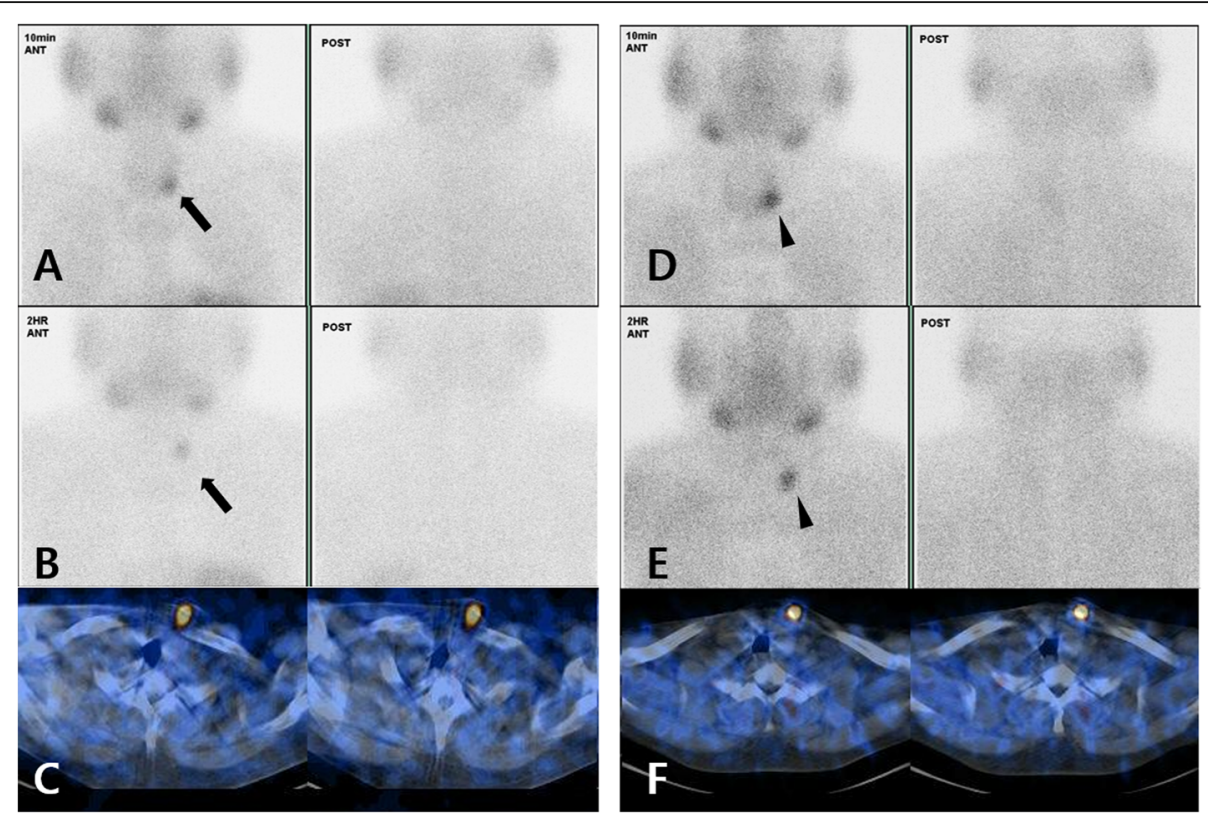

Fig. 2 Tc-99 m MIBI dual-phase parathyroid scintigraphy. a b cFocal increased uptake in clavicular head area of left sternocleidomastoid muscle (black arrow). Parathyroid Scintigraphy performed 3 years after total parathyroidectomy with auto-transplantation; (A) Early and wash-out images acquired at 10 min post injection; (b) Delayed and wash-out images acquired at 120 min post injection; (c) Axial fused images acquired at 120 min post injection; (d) (e) (f) A hyperfunctioning auto-transplanted parathyroid tissue with increased uptake was identified compared to previous scintigraphy (black arrowhead). Parathyroid Scintigraphy performed 8 years after total parathyroidectomy with auto-transplantation; (d) Early and wash-out images acquired at 10 min post injection; (e) Delayed and wash-out images acquired at 120 min post injection; (f) Axial fused images acquired at 120 min post injection
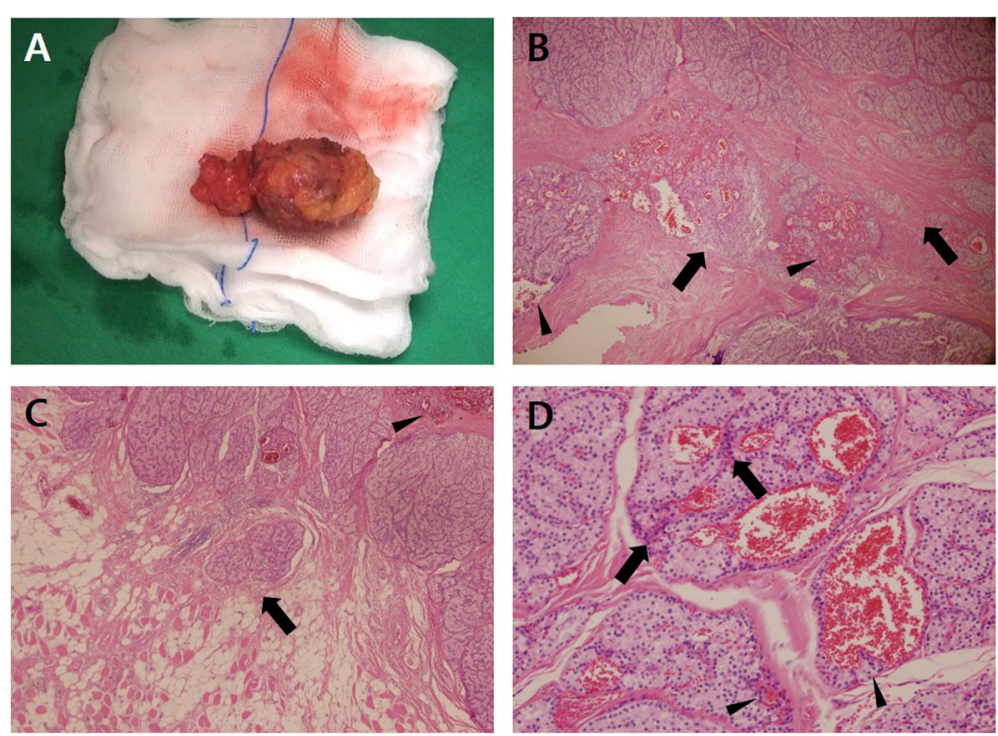

Fig. 3 Gross and pathologic findings of extirpated auto-transplanted parathyroid tissue. a Gross findings. A mass of about $2 \times 2 \mathrm{~cm}$ in size with solitary and irregular margins was identified; (B-D) Pathologic findings. b Invasion into surrounding muscular structure(black arrow) and vessels (black arrowhead) (H \& E, X 100); (c) Satellite lobule (black arrow) and partial necrotic finding (black arrowhead) (H \& E, X 100); (d) Highly mitotic feature of parathyroid cell (black arrow) and minimally invasion into vascular structure (black arrowhead) (H \& E, X 200) 
Total parathyroidectomy with or without autotransplantation or subtotal parathyroidectomy are the surgical methods of choice for the treatment of secondary hyperthyroidism. Total parathyroidectomy with auto-transplantation is preferred for patients who have reasons to avoid subsequent surgeries or long-term hemodialysis after surgery $[15,24]$. Total parathyroidectomy alone is useful for preventing the recurrence of secondary hyperparathyroidism in patients who do not have the potential for kidney transplantation and who have a long-life expectancy [25]. In this case study, the patient's secondary hyperparathyroidism persisted despite pharmacologic treatment, and surgical treatment was indicated. Although there was a risk of recurrence, total thyroidectomy with auto-transplantation was performed due to the possibility of future kidney retransplantation. Parathyroid carcinoma is a rare malignant tumor; the main cause is primary hyperparathyroidism [3]. Parathyroid carcinoma is commonly sporadic and may be associated with familiar primary hyperparathyroidism or jaw tumor syndrome [3, 5]. Rarely, a history of cervical irradiation or chronic stimulation, such as secondary hyperparathyroidism, is known to be the cause of parathyroid carcinoma [26].

Parathyroid carcinoma in patients with secondary hyperparathyroidism has been reported very rarely $[4$, 27], and parathyroid carcinoma in auto-transplanted parathyroid tissue has not been reported previously. Parathyromatosis is also a rare disease, but it is still more common in patients with secondary hyperparathyroidism than parathyroid carcinoma [28, 29]. Differential diagnosis between parathyroid carcinoma and parathyromatosis is an important focus. In our case, the mitotic features of the parathyroid cells were prominent under light microscopy, and the invasion of muscle and blood vessels was remarkable. Therefore, the pathologic diagnosis was confirmed as parathyroid carcinoma. Of course, these pathologic findings are not the definitive point of differential diagnosis between parathyroid carcinoma and parathyromatosis [5]. In this case, clinically, the patient was not hypercalcemic $(>14 \mathrm{mg} / \mathrm{dL})$ but 10 $\mathrm{mg} / \mathrm{dL}$ is relatively high for a hypocalcemia-associated CKD patient. In addition, the lesion appeared in the form of a solitary mass rather than multinodular, which is the characteristic form of parathyromatosis in autotransplanted parathyroid tissue [29]. These findings ultimately confirmed the diagnosis of parathyroid carcinoma, and adjuvant radiation therapy was ordered and performed.

This patient is the first reported case of parathyroid carcinoma arising from auto-transplanted parathyroid tissue after total parathyroidectomy resulting from secondary hyperparathyroidism. Although the disease incidence is rare, it is a result that cannot be overlooked in long-term dialysis patients, in whom chronic stimulation of parathyroid tissue is inevitable. Likewise, parathyromatosis, which occurs rarely in auto-transplanted parathyroid tissue, is considered a low-grade malignancy. Therefore, if total parathyroidectomy with autotransplantation is performed in patients with secondary hyperparathyroidism, continuous treatment and careful observation of the transplant site is necessary. In conclusion, we provisionally recommend total parathyroidectomy would be performed without auto-transplantation in secondary hyperparathyroidism patients, especially younger patients who have a long-life expectancy or those who are less likely to undergo renal transplantation as well as all patients who do not necessarily require auto-transplantation.

\section{Supplementary information}

Supplementary information accompanies this paper at https://doi.org/10. 1186/s12882-019-1606-5.

Additional file 1: Figure S1. Preoperative neck CT. (A) (B) Smal enhancing masses in the retrothyroidal area on both sides (black arrows). (A) Axial view; (B) Coronal view. Figure S2. Serologic test results. Elevated PTH and phosphorus decreased after total parathyroidectomy with autotransplantation (1st operation: 10/2011). Prior to complete resection (2nd operation: 03/2019) of the auto-transplanted parathyroid tissue, PTH and total calcium levels were increased while phosphorus remained normal. After complete resection, PTH and calcium levels decreased. All measurements represent the mean value.

\section{Abbreviations}

CKD: Chronic kidney disease; CT: Computed tomography; GFR: Glomerular filtration rate; PTH: Parathyroid hormone

\section{Acknowledgments}

This research was supported by the research fund of Chungnam National University.

\section{Authors' contributions}

HRW wrote the first draft. JYK, IHL, JMK and BSK were directly involved in the patient's care. JWC and BSK revised and edited the manuscript. All authors read and approved the final version of the manuscript

Funding

The authors received no specific funding for this work.

Availability of data and materials

The datasets used and/or analyzed during the current study available from the corresponding author on reasonable request.

Ethics approval and consent to participate

Not applicable.

Consent for publication

Written informed consent was obtained from the patient for publication of this Case Report and any accompanying images. Written informed consent is available on request.

Competing interests

None of the authors have a relevant financial relationship with a commercial interest.

\section{Author details}

${ }^{1}$ Department of Otolaryngology-Head and Neck Surgery, Chungnam National University College of Medicine, 640 Daesa-Dong, Chung-Gu, Daejeon 
301-721, Republic of Korea. ${ }^{2}$ Department of Radiology, Chungnam National University College of Medicine, Daejeon, Republic of Korea. ${ }^{3}$ Department of Pathology, Chungnam National University College of Medicine, Daejeon, Republic of Korea.

\section{Received: 18 July 2019 Accepted: 29 October 2019}

Published online: 15 November 2019

\section{References}

1. Komaba H, Kakuta T, Fukagawa M. Management of secondary hyperparathyroidism: how and why? Clin Exp Nephrol. 2017;21(Suppl 1):3745

2. Tentori F, Wang M, Bieber BA, Karaboyas A, Li Y, Jacobson SH, Andreucci VE, Fukagawa M, Frimat L, Mendelssohn DC, et al. Recent changes in therapeutic approaches and association with outcomes among patients with secondary hyperparathyroidism on chronic hemodialysis: the DOPPS study. Clin J Am Soc Nephrol. 2015;10(1):98-109.

3. Cetani F, Pardi E, Marcocci C. Update on parathyroid carcinoma. J Endocrinol Investig. 2016;39(6):595-606.

4. Takami H, Kameyama K, Nagakubo I. Parathyroid carcinoma in a patient receiving long-term hemodialysis. Surgery. 1999;125(2):239-40.

5. Fernandez-Ranvier GG, Khanafshar E, Jensen K, Zarnegar R, Lee J, Kebebew E, Duh QY, Clark OH. Parathyroid carcinoma, atypical parathyroid adenoma, or parathyromatosis? Cancer. 2007;110(2):255-64

6. Hindié $E$, Zanotti-Fregonara $P$, Just PA, Sarfati E, Mellière $D$, Toubert ME, Moretti JL, Jeanguillaume C, Keller I, Ureña-Torres P. Parathyroid scintigraphy findings in chronic kidney disease patients with recurrent hyperparathyroidism. Eur J Nucl Med Mol Imaging. 2010;37(3):623-34.

7. Saliba W, El-Haddad B. Secondary hyperparathyroidism: pathophysiology and treatment. J Am Board Fam Med. 2009;22(5):574-81.

8. Levey AS, Eckardt KU, Tsukamoto Y, Levin A, Coresh J, Rossert J, De Zeeuw D, Hostetter TH, Lameire N, Eknoyan G. Definition and classification of chronic kidney disease: a position statement from kidney disease: improving global outcomes (KDIGO). Kidney Int. 2005;67(6):2089-100.

9. Bell G, Huang S, Martin KJ, Block GA. A randomized, double-blind, phase 2 study evaluating the safety and efficacy of AMG 416 for the treatment of secondary hyperparathyroidism in hemodialysis patients. Curr Med Res Opin. 2015;31(5):943-52.

10. Cunningham J, Locatelli F, Rodriguez M. Secondary hyperparathyroidism: pathogenesis, disease progression, and therapeutic options. Clin J Am Soc Nephrol. 2011;6(4):913-21.

11. Komaba H, Taniguchi M, Wada A, Iseki K, Tsubakihara Y, Fukagawa M. Parathyroidectomy and survival among Japanese hemodialysis patients with secondary hyperparathyroidism. Kidney Int. 2015;88(2):350-9.

12. Block GA, Klassen PS, Lazarus JM, Ofsthun N, Lowrie EG, Chertow GM. Mineral metabolism, mortality, and morbidity in maintenance hemodialysis. J Am Soc Nephrol. 2004;15(8):2208-18.

13. Ganesh SK, Stack AG, Levin NW, Hulbert-Shearon T, Port FK. Association of elevated serum $\mathrm{PO}_{4}, \mathrm{Ca} \times \mathrm{PO}_{4}$ product, and parathyroid hormone with cardiac mortality risk in chronic hemodialysis patients. J Am Soc Nephrol. 2001;12(10):2131-8.

14. Levin A, Bakris GL, Molitch M, Smulders M, Tian J, Williams LA, Andress DL. Prevalence of abnormal serum vitamin D, PTH, calcium, and phosphorus in patients with chronic kidney disease: results of the study to evaluate early kidney disease. Kidney Int. 2007;71(1):31-8.

15. Lau WL, Obi Y, Kalantar-Zadeh K. Parathyroidectomy in the management of secondary hyperparathyroidism. Clin J Am Soc Nephrol. 2018;13(6):952-61.

16. Komaba H, Fukagawa M. FGF23-parathyroid interaction: implications in chronic kidney disease. Kidney Int. 2010:77(4):292-8.

17. Slatopolsky E, Finch J, Denda M, Ritter C, Zhong M, Dusso A, MacDonald PN, Brown AJ. Phosphorus restriction prevents parathyroid gland growth. High phosphorus directly stimulates PTH secretion in vitro. J Clin Invest. 1996; 97(11):2534-40.

18. Schneider R, Bartsch DK. Role of surgery in the treatment of renal secondary hyperparathyroidism. Br J Surg. 2015;102(4):289-90.

19. Investigators ET, Chertow GM, Block GA, Correa-Rotter R, Drueke TB, Floege J, Goodman WG, Herzog CA, Kubo Y, London GM, et al. Effect of cinacalcet on cardiovascular disease in patients undergoing dialysis. N Engl J Med. 2012;367(26):2482-94.

20. Block GA, Bushinsky DA, Cunningham J, Drueke TB, Ketteler M, Kewalramani R, Martin KJ, Mix TC, Moe SM, Patel UD, et al. Effect of Etelcalcetide vs placebo on serum parathyroid hormone in patients receiving hemodialysis with secondary hyperparathyroidism: two randomized clinical trials. JAMA 2017;317(2):146-55.

21. Tominaga Y, Tanaka Y, Sato K, Nagasaka T, Takagi H. Histopathology, pathophysiology, and indications for surgical treatment of renal hyperparathyroidism. Semin Surg Oncol. 1997;13(2):78-86.

22. Ketteler M, Block GA, Evenepoel P, Fukagawa M, Herzog CA, McCann L, Moe SM, Shroff R, Tonelli MA, Toussaint ND, et al. Executive summary of the 2017 KDIGO chronic kidney disease-mineral and bone disorder (CKD-MBD) guideline update: what's changed and why it matters. Kidney Int. 2017; 92(1):26-36.

23. Schneider R, Slater EP, Karakas E, Bartsch DK, Schlosser K. Initial parathyroid surgery in 606 patients with renal hyperparathyroidism. World J Surg. 2012; 36(2):318-26.

24. Tominaga $Y$, Numano $M$, Tanaka $Y$, Uchida $K$, Takagi $H$. Surgical treatment of renal hyperparathyroidism. Semin Surg Oncol. 1997;13(2):87-96.

25. Liu ME, Qiu NC, Zha SL, Du ZP, Wang YF, Wang Q, Chen $Q$, Cen XX, Jiang Y, Luo $Q$, et al. To assess the effects of parathyroidectomy (TPTX versus TPTX+ AT) for secondary hyperparathyroidism in chronic renal failure: a systematic review and meta-analysis. Int J Surg. 2017:44:353-62.

26. Marcocci C, Cetani F, Rubin MR, Silverberg SJ, Pinchera A, Bilezikian JP. Parathyroid carcinoma. J Bone Miner Res. 2008:23(12):1869-80.

27. Berland Y, Olmer M, Lebreuil G, Grisoli J. Parathyroid carcinoma, adenoma and hyperplasia in a case of chronic renal insufficiency on dialysis. Clin Nephrol. 1982;18(3):154-8.

28. Stehman-Breen C, Muirhead N, Thorning D, Sherrard D. Secondary hyperparathyroidism complicated by parathyromatosis. Am J Kidney Dis. 1996;28(4):502-7.

29. Falvo L, Catania A, Sorrenti S, D'Andrea V, Santulli M, De Antoni E. Relapsing secondary hyperparathyroidism due to multiple nodular formations after total parathyroidectomy with autograft. Am Surg. 2003;69(11):998-1002.

\section{Publisher's Note}

Springer Nature remains neutral with regard to jurisdictional claims in published maps and institutional affiliations.
Ready to submit your research? Choose BMC and benefit from:

- fast, convenient online submission

- thorough peer review by experienced researchers in your field

- rapid publication on acceptance

- support for research data, including large and complex data types

- gold Open Access which fosters wider collaboration and increased citations

- maximum visibility for your research: over $100 \mathrm{M}$ website views per year

At BMC, research is always in progress.

Learn more biomedcentral.com/submissions 